\title{
Analysis of Acoustic Pressure Fluctuation around Wind Farms
}

\author{
Adam Zagubień* \\ Koszalin University of Technology, Faculty of Civil Engineering, Environmental and Geodetic Sciences, \\ Koszalin, Poland
}

Received: 24 October 2017

Accepted: 2 December 2017

\begin{abstract}
The aim of this study was to assess the discrepancies of the results of equivalent sound levels measured locally in relation to changes in acoustic pressure. The article studies both single turbines and wind farms, where fluctuations in acoustic pressure are clearly audible. The object of this study was turbines in northwestern and central Poland, which were studied either as single objects or as a group (several turbines together in one wind farm). Presented results of measurements were selected in terms of significant disturbances. Despite this process, it was impossible to eliminate the influence of gusts of wind that showed up in almost all graphs, especially in measurement points of $500 \mathrm{~m}$ distance from the edge of a turbine tower. It was noticed that during sound emissions not all turbines show significant fluctuation of acoustic pressure levels. It was pointed out that equivalent sound level $\mathrm{L}_{\text {AeqT }}$ - which in most countries is the indicator of acoustic climate assessment - forms the above statistical average $\mathrm{L}_{\mathrm{A} 50}$ calculated from the measurement of acoustic pressure level SPL and regards the changeability of acoustic pressure levels in time.
\end{abstract}

Keywords: noise propagation, modulation of noise amplitude, noise level fluctuations, wind turbine, noise measurements, noise character

\section{Introduction}

The main aim of this study was to estimate the discrepancies of results of equivalent sound level $\left(\mathrm{L}_{\mathrm{AeqT}}\right)$ measured locally, and the SPL changes of acoustic pressure level during measurement. Changes of measured acoustic pressure level in time occur during field measurements independently from the source, which is

*e-mail: adam.zagubien@tu.koszalin.pl the object of the study. In the case of some sources - for example air conditioners - the changes are little, at up to $4 \mathrm{~dB}$. Other sources, like for instance road traffic, show higher than $10 \mathrm{~dB}$ fluctuations of acoustic pressure level in any observation time (Fig. 1).

Cyclical fluctuations of audible noise levels of wind turbines registered at the turbine main tower, especially connected with the frequency of rotor blade passing the turbine main tower,mare called by many researchers a modulation of noise amplitude [1-3]. However, the author of this article uses the term "fluctuation of 


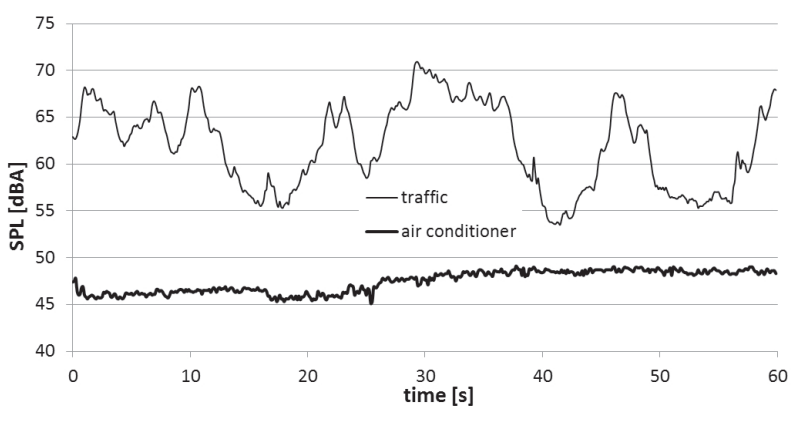

Fig. 1. Sample fluctuations of acoustic pressure level.

acoustic pressure level," taking into account different disturbances of registered signals in a distance of $500 \mathrm{~m}$, where there is usually the first line of building complexes protected acoustically. When it comes to protection of the environment against noise in areas where people live, the level of acoustic pressure - limited by permissible level is very important. The places of location of wind turbine towers have no assigned permissible noise levels.

This article studies both single turbines and wind farms where the fluctuations of acoustic pressure are clearly audible. During wind farm operation there are specific acoustic and non-acoustic phenomena, characteristic of this sound source described in many publications [4-10], the most essential being:

- The acoustic power level of wind turbines available in the market is diverse. Moreover, it is changeable during operation depending on wind speed and increases together with wind speed, and after reaching a certain terminal velocity it becomes practically constant.

- Fluctuation of acoustic pressure level depending on wind speed - in many publications defined as modulation of noise amplitude [1-3, 11].

- Wind speed increases with the change of height above ground level: the higher it is, the greater the wind speed.

- The level of acoustic background changes with the wind speed, increasing with speed.

- With the increase of wind speed the part of acoustic background in measured total noise level has a growing tendency. At higher wind speeds, close to matching maximum efficiency and maximum acoustic power level of turbines, the level of background in a measurement point becomes comparable to the noise level of working turbines. One of the most essential reasons for this situation is a significant distance from the source measurement control points (more than $400 \mathrm{~m}$ ) located near the closest housing complex. Fluctuation in acoustic pressure near wind turbines is mainly connected with the following factors:

- Changes of wind speed in time described as gusts of wind registered in Poland, especially in an area up to $100 \mathrm{~km}$ from the sea.

- Rotary motion of a propeller, causing a characteristic whistling of blade tips in some turbines.

- Cyclic movement of the propeller near the main tower of a turbine.

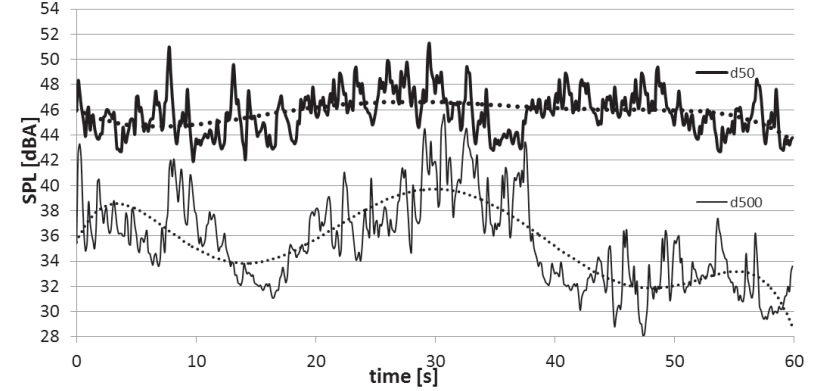

Fig. 2. Sample fluctuations of acoustic pressure level around the wind farm .

The above phenomena are illustrated in Fig. 2. The results are presented for the two measurement points located $50 \mathrm{~m}(\mathrm{~d} 50)$ and $500 \mathrm{~m}(\mathrm{~d} 500)$ from the edge turbine of the wind farm. The dashed line marks the changes of acoustic pressure level caused by gusts of wind.

Calculations of the range of noise emitted by wind turbines can be made by computer programs using different calculation algorithms [12]. The review and comparison of different calculation algorithms is discussed in many publications [13-14], in which the calculated results are compared with the local measurements. The calculation algorithm of ISO 9613-2 norm [15] belongs to mostly used ones in the world. In most countries, the calculated result is very often defined as a single number indicator $\mathrm{L}_{\text {AeqT }}$ (equivalent sound level) separately for day and night. However, calculation algorithms base on averaged indicators (acoustic power level) and do not regard the fluctuation of acoustic pressure level in time.

Local measurements of noise from wind turbines in chosen control points are conducted in a similar way by many researchers. Mostly they measure the equivalent sound level $\mathrm{L}_{\text {AeqT }}$ (1) or statistical levels $\mathrm{L}_{\mathrm{A} 90}, \mathrm{~L}_{\mathrm{A} 50}$, $\mathrm{L}_{\mathrm{A} 10}$ (the sound level being exceeded for $90 \%, 50 \%$, or $10 \%$ of the measurement period) - depending on recommended measuring procedures and assessment criteria in force in a certain country. The equivalent A-weighted sound level is expressed in $\mathrm{dB}$ and given by the formula:

$$
L_{\text {Aeq,Te }}=10 \lg \left[\frac{1}{T_{e}} \int_{0}^{T_{e}}\left(\frac{p_{A}(t)}{p_{0}}\right)^{2} d t\right]
$$

...where $L_{\text {Aeq,Te }}$ is equivalent A-weighted sound level; $T_{e}$ is time of exposure; $p_{A}$ is instantaneous value of an acoustic pressure, corrected according to the frequency-weighting characteristics $\mathrm{A}$; and $p_{0}$ is reference pressure.

It is obvious that levels $\mathrm{L}_{\text {AeqT }}$ taken from measurements or $\mathrm{L}_{\mathrm{A} 90}, \mathrm{~L}_{\mathrm{A} 50}$, and $\mathrm{L}_{\mathrm{A} 10}$ levels include the influence of fluctuation of acoustic power level in study time in a different degree. However, it is doubtful whether the specified indicator is adequate for people living near a wind farm. Research connected with taking into consideration 
the influence of the fluctuation of acoustic pressure level has been done in several countries, for instance in Japan [2], and advanced studies in Great Britain [16].

Wind turbine producers provide a changeable acoustic power of their devices in relation to wind speed changes measured at the height of $10 \mathrm{~m}$ above the ground. They do not provide the ranges of changes of acoustic pressure levels in time registered during determining the acoustic power of turbines in specifications of a certain type of turbine.

\section{Experimental}

Values registered during measurements were the changes of acoustic pressure levels SPL in time at sample constant time "fast" (8 samples per second). The measurements were conducted by a class 1 SVAN 912AE digital sound analyser with wind-protection cover, enabling the simultaneous measurement of most parameters characterising the noise. Before and after measurements, the measuring track and the sound analyser were checked by a class 1 calibrator. The whole measurement set had necessary calibration certificates.

Conducted measurements set two heights of wind speed. The first value, the momentary one, was defined at the height of $4.0 \mathrm{~m}$ with the rule that it must be less than $6 \mathrm{~m} / \mathrm{s}$. During noise measurements, the average wind speed above $5 \mathrm{~m} / \mathrm{s}$, in many cases, renders impossible differentiating the measured source from acoustic background level [4, 10, 12, 17-18]. The second value, the average, was defined on the basis of readings from anemometers installed at the height of the rotor axis of a wind turbine. There were used computer records of average wind speeds at each turbine, registered at the time of measurements in 10-minute periods that were provided by wind farm operators. The measurements were conducted in the following weather conditions: $5-15^{\circ} \mathrm{C}$, humidity $60-80 \%$, pressure $980-1020 \mathrm{hPa}$, and momentary wind speed at the height of measurement point 3.0-6.0 m/s. The measurements were conducted by a portable meteo station with valid calibration certificate.

During measurements there were taken into consideration all specific phenomena connected with wind turbines operation that influence noise. At the beginning there was a plan to register the measurements in a continuous way for a couple of hours at each measuring point. However, due to many disturbances caused by field work nearby, sounds of animals and noises of vehicles passing by, and also changeable values of wind speed, it was reasonable to decide to take sound samples. The authors of the publication [19] indicate relatively small changeability of the vertical profile of wind speed within 10 minutes. There were 5-10 measurement samples in each measurement point. The time of measurement of one sample was 60 s. Samples with significant disturbances were excluded. After measurements of changes of acoustic pressure levels the turbines were stopped and there were carried out the measurements of changes of acoustic pressure levels of the background, in the same measurement points, and at similar weather conditions. This was necessary to make sure if other non-identified sources have no influence on registered changes of acoustic pressure levels. The measurement height was set at $4 \mathrm{~m}$ above the ground in order to decrease the influence of sound wave reflection caused by hard terrain in some measurement points. Moreover, in many countries at the height of $4 \mathrm{~m}$ above the ground they check the criteria of protection of the environment against noise. In cases where measurement points are located near dwellings, the distance from the elevation was more than $4 \mathrm{~m}$, so there was no correction of measurement results regarding the reflected wave. The measurement points were located $50 \mathrm{~m}$ and $500 \mathrm{~m}$ from a single or edge wind farm. The measurement was conducted both from the leeward and windward sides. However, due to small fluctuations of acoustic pressure levels during propagation upwind, there were presented the results only at sound wave propagation downwind to the control point.

Both single turbines and groups of turbines were analyzed. Wind farms were located mostly in northern Poland, plus one in central Poland. Turbine power ranged 1.6-3.0 MW. They were made by known producers and have been installed all over the world. They were 1 to 10 years old. The names and the locations of turbines are not mentioned. The turbines are described in studies by power, tower height, and rotation speed of the rotor. All studied turbines had three-blade rotors. The subjects of studies were chosen in the way to measure the changes of acoustic pressure for different types of turbines installed at different heights above ground level. All wind farms were located on flat or slightly rolling terrain, and maximum differences in heights were up to 5 meters.

\section{Results and Discussion}

The measurements were conducted during environmental monitoring at chosen wind farms in order to study the influence of these farms on areas protected acoustically, which made it possible to measure the acoustic background after stopping the turbines. Presented measurement results do not regard the assessment of the influence of wind turbines on the environment. The location of measurement points very often did not match the points located at acoustically protected areas in order to avoid disturbances caused by site development and installations. Results presented in this chapter (in change graphs - SPL in time) were selected for lack of disturbances and they are representative for a studied measurement point. The exception are the graphs in Fig. 3, which regard the low emission levels of a turbine containing almost only disturbances - measuring background. Wind turbines work at different rotation speeds in a certain range depending on wind speed. The range of changes in rotation speed of a rotor depends on the type of turbine and rotor diameter, ranging from 7 to $30 \mathrm{rpm}$. For example, 


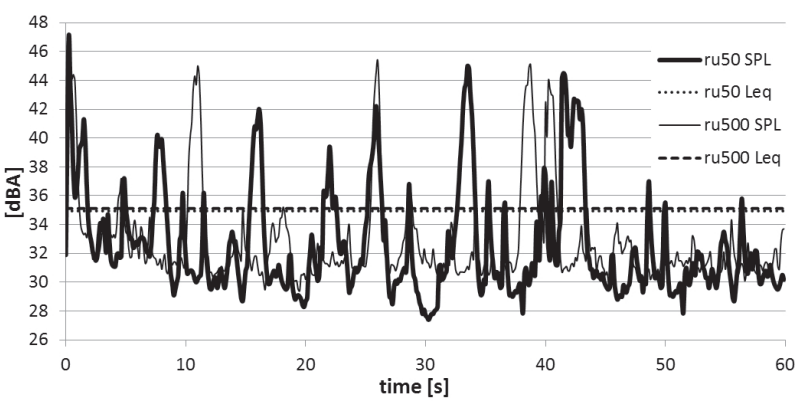

Fig. 3. SPL fluctuations during work of turbines with lower rotation speed of a rotor.

for turbines of small power of $0.66 \mathrm{MW}$ and a small rotor diameter (e.g., $47 \mathrm{~m}$ ), the maximum number of turns may be $28.5 \mathrm{rpm}$ [20]. There were studied the turbines of bigger power (1.6-3.0 MW), which at a low wind speed of about $4 \mathrm{~m} / \mathrm{s}$ at the height of a rotor axis cause rotation frequency of $8 \mathrm{rpm}$, and the maximum number of turns at wind speed of $11 \mathrm{~m} / \mathrm{s}$ at the height of the rotor axis is $22 \mathrm{rpm}$. Generally, the greater the power of the turbine and the rotor diameter, the smaller the maximum rotation speed of the rotor. Rotors of modern turbines of $3 \mathrm{MW}$ and rotor diameter of more than $100 \mathrm{~m}$ do not exceed the rotation speed of $18 \mathrm{rpm}$. The amount of produced energy and also the acoustic power depends on the rotation speed of a rotor. For studied wind turbines, acoustic power at small, initial, and rotation speed of a rotor was below $94 \mathrm{dBA}$, and at maximum rotation speed of a rotor it was about $105 \mathrm{dBA}$. The above data come from technical documentation and are publicly available [20-22].

\section{Work of Turbines at Lower Rotor Rotation Speeds}

The measurement of changes of acoustic pressure SPL during working turbines with lower rotation speeds of 8-10 rpm and at light wind of 4-6 $\mathrm{m} / \mathrm{s}$ at the height of rotor axis at 80-120 m above the ground, showed the randomness of registered levels (Fig. 3). Recorded SPL changes at a distance of $50 \mathrm{~m}$ (ru50) and $500 \mathrm{~m}$ (ru500) from the edge tower related to almost only values of acoustic background. In Fig. 3, a separate dashed line

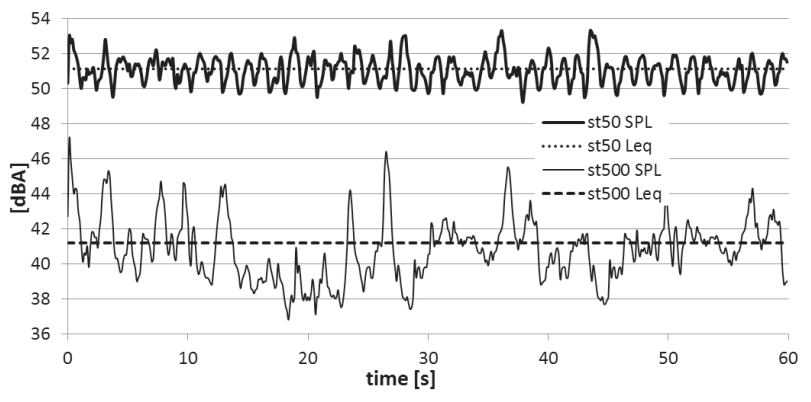

Fig. 4. SPL fluctuations during work of a single turbine at maximum rotation speed of a rotor.

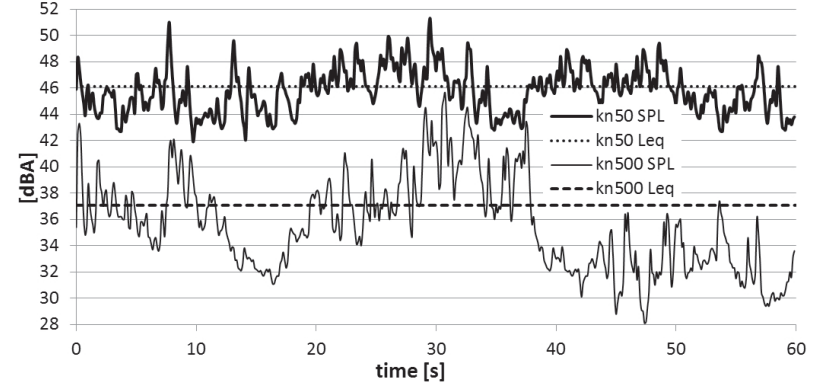

Fig. 5. SPL fluctuations during work of a single turbine at maximum rotation speed of a rotor.

marks the equivalent sound level, $\mathrm{L}_{\text {AeqT }}$, related to each 60 -second sample of SPL changes. Corresponding lines defining calculated equivalent sound levels point out that there was registered mainly the level of acoustic background. Significant changes of acoustic pressure level were caused by natural sounds, mainly bird calls flying nearby and barking dogs from distant homes.

\section{Work of a Single Turbine at Maximum Rotor Rotation Speed}

Measurements of changes of acoustic pressure were conducted during the work of a single wind turbine at close to maximum rotation speed of a rotor, at wind speed of $10 \mathrm{~m} / \mathrm{s}$ at the height of rotor axis. Two locations of wind turbines were analyzed. The first turbine was $1.6 \mathrm{MW}$, tower height $80 \mathrm{~m}$, and rotation speed $22 \mathrm{rpm}$ (Fig. 4). The second one was $2.0 \mathrm{MW}, 98 \mathrm{~m}$, and rotation speed $16 \mathrm{rpm}$ (Fig. 5). Registered SPL changes $50 \mathrm{~m}$ (st50) and $500 \mathrm{~m}$ (st500) from the tower are related to the first location (Fig. 4). Registered SPL changes $50 \mathrm{~m}$ (st50) and $500 \mathrm{~m}$ (st500) from the tower relate to the second location (Fig. 5). Additionally, on both graphs a separate dashed line marks $\mathrm{L}_{\text {Aeq }}$ related to each 60 -second sample of SPL changes.

\section{Work of a Group of Turbines at Maximum Rotation Speed of a Rotor}

Measurements of changes of SPL acoustic pressure were conducted during the work of wind farms at close

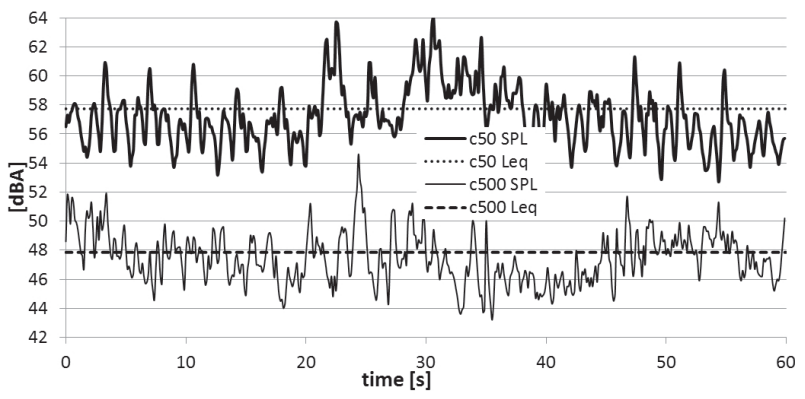

Fig. 6. SPL fluctuations during wind farm work at maximum rotation speed of a rotor. 


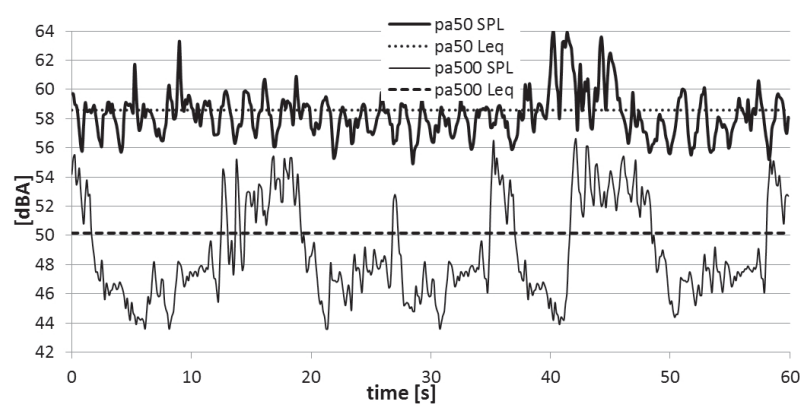

Fig. 7. SPL fluctuations during work of Farm II at maximum rotation speed of rotor.

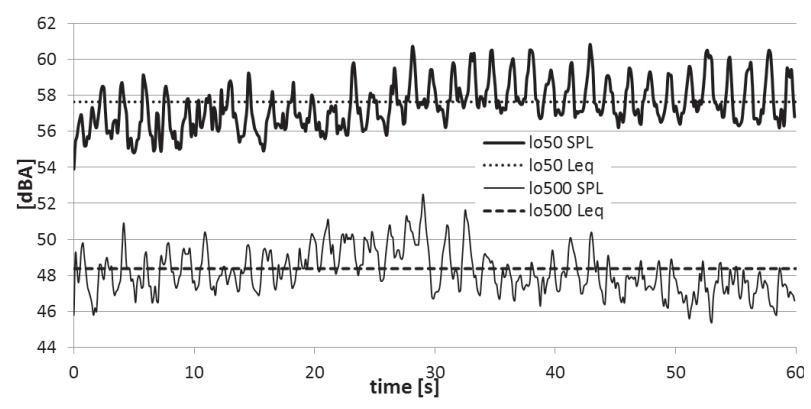

Fig. 8. SPL fluctuations during work of Farm III at maximum rotation speed of rotor.

to maximum rotation speed of rotors, at wind speed of above $10 \mathrm{~m} / \mathrm{s}$ at the height of rotor axis. Additionally, on the graphs a separate dashed line marks $\mathrm{L}_{\text {AeqT }}$ related to each 60 -second sample of SPL changes. Four locations of wind turbines were analyzed. The farm consisted of $102.0 \mathrm{MW} 80 \mathrm{~m}$ turbines at $22 \mathrm{rpm}$. Registered SPL changes $50 \mathrm{~m}$ (c50) and $500 \mathrm{~m}$ (c500) from the edge of the farm are presented in Fig. 6.

Farm II consisted of $162.0 \mathrm{MW} 100 \mathrm{~m}$ turbines at $14 \mathrm{rpm}$. Registered SPL changes $50 \mathrm{~m}$ (pa50) and $500 \mathrm{~m}$ (pa500) from the edge of the farm are presented in Fig. 7.

Farm III consisted of $303.0 \mathrm{MW} 90 \mathrm{~m}$ turbines of at $14 \mathrm{rpm}$. Registered SPL changes $50 \mathrm{~m}$ (lo50) and $500 \mathrm{~m}$ (lo500) from the farm are presented in Fig. 8.

Farm IV consisted of $123.0 \mathrm{MW} 120 \mathrm{~m}$ turbines at $15 \mathrm{rpm}$. Registered SPL changes $50 \mathrm{~m}$ (sz50) and $500 \mathrm{~m}$

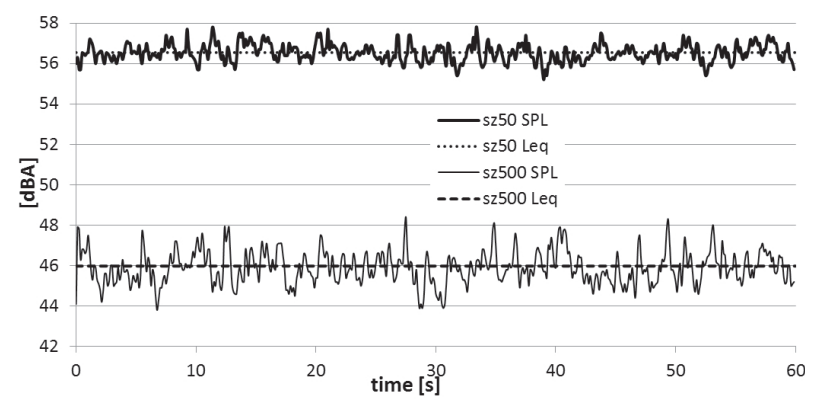

Fig. 9. SPL fluctuations during work of Farm IV at maximum rotation speed of a rotor.

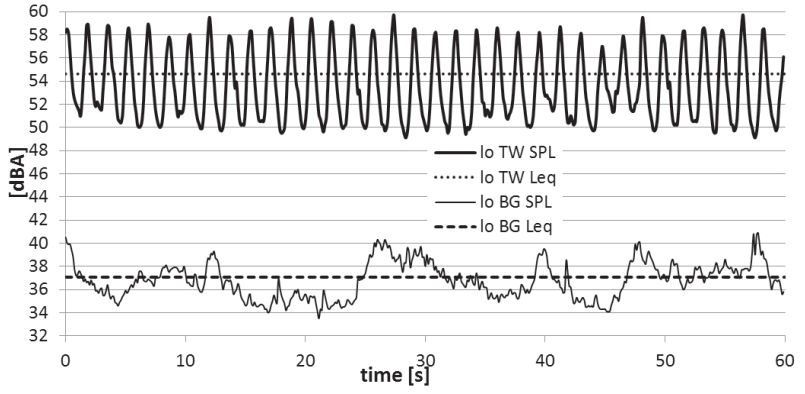

Fig. 10. SPL fluctuations during work of Farm III measured near the turbine and the level of acoustic background.

(sz500) from the farm are presented in Fig. 9.

\section{Measurements at a Wind Turbine Tower}

For example, Fig. 10 presents the SPL measurement results $5 \mathrm{~m}$ (lo TW) from the turbine and the level of changes of acoustic background (lo BG) registered after stopping all turbines for Farm III. In the graph lo TW SPL we simply calculate the rotation frequency of a turbine during measurement, which is 36 peak values divided by 3 blades, which gives us $12 \mathrm{rpm}$.

\section{Conclusions}

The indicator of noise assessment in environment in the form of $\mathrm{L}_{\text {AeqT }}$ for day and night time is applied in most countries, and New Zeeland, Australia, and Great Britain apply statistical indicators $\left(\mathrm{L}_{\mathrm{A} 90}\right)$. The differences of above indicators and the $\mathrm{L}_{\mathrm{A} 90}$ indicator in relation to changes of acoustic pressure level at the studied turbine are presented in Fig. 11.

Table 1 presents estimated discrepancies between the equivalent sound level $\mathrm{L}_{\text {AeqT }}$ measured at the site and the changes of SPL acoustic pressure level. It was assumed that changes up to $2 \mathrm{~dB}$ above the equivalent sound level $\mathrm{L}_{\mathrm{AeqT}}$ are barely sensed by a human ear [23-24], and they are within measurement error margin [4]. The analysis was conducted $500 \mathrm{~m}$ from the edge tower of the wind farm, representative for the closest acoustically protected

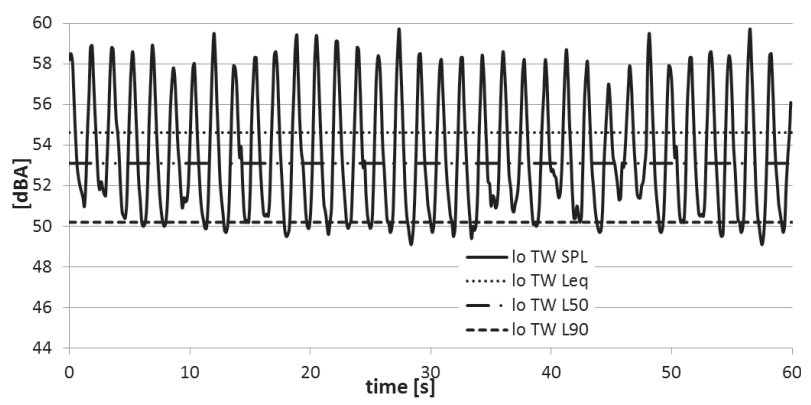

Fig. 11. SPL fluctuations against the background of indicators $\mathrm{L}_{\text {eq }}, \mathrm{L}_{50}$, and $\mathrm{L}_{90}$ at the studied turbine. 
Table 1. Estimating the discrepancies of $\mathrm{L}_{\text {AeqT }}$ results in relation to SPL changes.

\begin{tabular}{|c|c|c|c|}
\hline \multirow{2}{*}{ No. } & Name of a wind farm & $\begin{array}{c}\text { Assessment criteria } \\
\mathrm{L}=\mathrm{L}_{\text {Aeq }}+2\end{array}$ & Number of results exceeding the limit value L \\
\cline { 2 - 4 } & 2 & $(\mathrm{~dB})$ & 4 \\
\hline 1 & Farm I - Fig. 6 & 3 & 7.71 \\
\hline F1 & Farm II - Fig. 7 & 49.9 & 24.17 \\
\hline F2 & Farm III - Fig. 8 & 52.2 & 3.75 \\
\hline F3 & Farm IV - Fig. 9 & 50.4 & 0.83 \\
\hline F4 & Single turbine - Fig. 4 & 48.0 & 9.79 \\
\hline F5 & Single turbine - Fig. 5 & 43.2 & 15.41 \\
\hline F6 & & 39.1 & \\
\hline
\end{tabular}

building complex. Table 1 shows a percentage of the share of changes of acoustic pressure level exceeding the limit: $\mathrm{L}=\mathrm{L}_{\text {AeqT }}+2 \mathrm{~dB}$ in an analyzed attempt - column 4.

The values in column 4 for F2 and F6, Table 1, exceeding $10 \%$ criteria, are definitely caused by gusts of wind because of changes of acoustic pressure in time shown in Figs 7 and 5. They are very close to changes of acoustic pressure in time presented in Fig. 10. Other values in column 4 , Table 1 that do not exceed $10 \%$ criteria are characterised by momentary, accidental, and increased acoustic pressure levels and there is not any cyclicality to them.

Thanks to conducted research of changes of acoustic pressure SPL, on many farms, it is possible to form following conclusions:

1) Conducting a non-disturbed noise measurement in a natural environment is possible only when the measured source emits sound levels that are $10 \mathrm{~dB}$ higher than acoustic background level. In cases of measurements around wind farms moved by wind it is possible only near the main tower of the device.

2) Presented results of measurements were selected in terms of significant disturbances. Despite this process, it was impossible to eliminate the influence of gusts of wind showing in almost all graphs - especially in measurement points $500 \mathrm{~m}$ from the edge turbine tower.

3) Not all turbines show fluctuations of acoustic pressure level greater than $4 \mathrm{~dB}$ during sound emission - for example Farm IV (Fig. 9 and Table 1).

4) $\mathrm{L}_{\text {AeqT }}$, which in many countries is the indicator of acoustic climate assessment, forms above the statistical mean $\mathrm{L}_{\mathrm{A} 50}$ from SPL measurement (Fig. 11). It regards the changeability of acoustic pressure level in time.

5) It does not require any additional correction minding the fluctuation of acoustic pressure level SPL in time.

6) Statistical level $\mathrm{L}_{\mathrm{A} 90}$, which is the indicator of assessment of acoustic climate in a few countries, requires adding a correction indicator that regards the fluctuation of acoustic pressure level in time. In Great
Britain there is advanced research of estimating this correction indicator.

7) Due to the significant distance of a building complex protected acoustically from the source, fluctuations of acoustic pressure level - which are so clear at the turbine tower - are accidental and disturbed by acoustic background at a distance of $500 \mathrm{~m}$.

8) Each location of a wind farm requires an individual analysis of the area and the infrastructure surrounding the farm. Control and local measurements should be conducted under various weather conditions and at various wind directions, for example in all four seasons. Such a procedure allows for regarding the influence of most essential factors on acoustic climate in a control point.

9) Presented measurement results concern wind farms located in northern and central Poland. It is not certain whether for other locations - for example in mountain areas or areas of no greenery - the results of fluctuation of acoustic pressure level SPL in time would be similar.

\section{References}

1. SEONG Y., LEE S., GWAK D., CHO Y., HONG J., LEE S. An experimental study on annoyance scale for assessment of wind turbine noise. Journal of Renewable and Sustainable Energy, 5, 52008-1, 2013.

2. TACHIBANA H., YANO H., FUKUSHIMA A., SUEOKA S. Nationwide field measurements of wind turbine noise in Japan. Noise Control Engineering Journal, 62 (2), 90, 2014.

3. VON HÜNERBEIN S., PIPER B. Affective response to amplitude modulated wind turbine noise, in 6th International Meeting on Wind Turbine Noise, April 20-23, Glasgow, UK, 2015.

4. BULLMORE A., ADCOCK J., JIGGINS M., CAND M. Wind farm noise predictions and comparison with measurements, in the Third International Meeting on Wind Turbine Noise, 17-19 June, Aalborg, Denmark, 2009.

5. LIN B., XIAOFENG L., XINGXI H. Measurement system for wind turbines noises assessment based on LabVIEW. Measurement, 44 (2), 445, 2011. 
6. TONIN R. Sources of wind turbine noise and sound propagation. Acoustics Australia, 40, 20, 2012.

7. BOCKSTAEL A., DEKONINCK L., CAN A., OLDONI D., DE COENSEL B., BOTTELDOOREN D. Reduction of wind turbine noise annoyance: an operational approach. Acta Acustica united with Acustica, 98, 392, 2012.

8. WSZOŁEK T., KŁACZYŃSKI $M$. Problems in Measurements of Noise Indicators for Wind Turbines in Poland, in Forum Acusticum, 7-12 September, Cracow, Poland, 2014.

9. IANNACE G. Effects of noise from wind turbines inside home. Wind Engineering, 40, 25, 2016.

10. INGIELEWICZ R., ZAGUBIEŃ A. Problems of assessment of wind farm noise on the basis of local control measurements. Rocznik Ochrona Srodowiska, 18, 531, 2016 [In Polish].

11. OERLEMANS S. Effect of Wind Shear on Amplitude Modulation of Wind Turbine Noise. International Journal of Aeroacoustics, 14 (5-6), 729, 2015.

12. ZAGUBIEN' A., INGIELEWICZ R. The analysis of similarity of calculation results and local measurements of wind farm noise. Measurement, 106, 211, 2017.

13. PROSPATHOPOULOS J.M., VOUTSINAS S.G. Application of a ray theory model to the prediction of noise emissions from isolated wind turbines and wind parks. Wind Energy, 10, 103, 2007.

14. EVANS T., COOPER J. Comparison of predicted and measured wind farm noise levels and implications for assessments of new Wind Farm. Acoustics Australia, 40, $28,2012$.

15. ISO 9613-2:1996. Acoustics - Attenuation of sound during propagation outdoors Part 2: General method of calculation. International Standard, 1996.
16. WSP Wind turbine am review. Phase 2 Report. Department of Energy \& Climate Change Project no: 3514482A. Publisher: WSP Parsons Brinckerhoff, Bristol, 2016.

17. BUTKUS D., GRUBILIAUSKAS R., MAŽUOLIS J. Research of Equivalent and Maximum Value of Noise Generated by Wind Power Plants. Journal of Environmental Engineering and Landscape Management, 20 (1), $27,2012$.

18. INGIELEWICZ R., ZAGUBIEŃ A. Infrasound noise of natural sources in environment and infrasound noise of wind turbines. Polish Journal of Environmental Studies, 23, 1323, 2014

19. RO K.S., HUNT P.G. Characteristic Wind Speed Distributions and Reliability of the Logarithmic Wind Profile. Journal of Environmental Engineering, 133 (3), 313, 2007.

20. VESTAS General Specification $660 \mathrm{~kW}$ Variable Slip Wind Turbines. Item no.: 943111.R4. Publisher: Vestas, Denmark, 2000.

21. NORDEX Technical description Nordex N90/2500. Doc.: K0801_021434_en. Publisher: Nordex Energy GmbH, Germany, 2010.

22. ACCIONA General documentation AW3000 Technical description. Doc.: DG178034, Publisher: Acciona Windpower, Spain, 2014.

23. DITTRICH K., OBERFELD, D. A comparison of the temporal weighting of annoyance and loudness. Journal of the Acoustical Society of America, 126 (6), 3168, 2009.

24. COWAN J.P. The effects of sound on people, Publisher: John Wiley \& Sons, United Kingdom, 2016. 
